\title{
AS POLÍTICAS DE INFORMAÇÃO DIGITAL ADOTADAS NAS ESCOLAS PÚBLICAS NO NORDESTE
}

\author{
LAS POLÍTICAS DE INFORMACIÓN DIGITAL \\ ADOPTADAS EN LAS ESCUELAS PÚBLICAS EN EL \\ NORDESTE
}

\author{
Eunice Jesus Santos * \\ Ana Paula Oliveira Villalobos **
}

\begin{abstract}
RESUMO:
Introdução: As experiências na educação com a tecnologia digital em sala de aula são verificadas em diferentes regiões brasileiras, viabilizadas através dos diversos dispositivos digitais, seja o celular, tablet ou notebook. Objetivos: Analisar as políticas de informação digital adotadas nas escolas públicas de ensino médio das capitais, localizadas na região Nordeste, no tocante a adoção dos dispositivos móveis para acesso a informação. Metodologia: Trata-se de pesquisa descritiva, com uma abordagem que se caracteriza enquanto qualitativa e quantitativa. Os procedimentos adotados se referem ao estudo de casos múltiplos e as técnicas basearam-se em questionários com professores das nove unidades federativas da região Nordeste. Resultados: O tablet é uma das tecnologias móveis menos utilizadas pelos professores. O celular e o notebook são ferramentas de trabalho mais utilizadas pelos professores nas aulas, não encontrando nenhuma dificuldade no uso e os resultados obtidos com essas tecnologias móveis em sala de aula, agregam valor na aquisição do conhecimento com relação às aulas sem o auxílio dessas tecnologias. Conclusão: Foram identificados exemplos de políticas de informação digital nas escolas em Fortaleza (CE) e em João Pessoa (PB) que podem servir como base na criação de uma política de informação digital em outros estados.
\end{abstract}

Palavras-chave: Tecnologia da Informação. Dispositivo móvel. Política de Informação digital. Uso do celular, tablet e notebook. Educação no Nordeste brasileiro.

\footnotetext{
*Mestre em Ciência da Informação pela Universidade Federal da Bahia. E-mail: santosnice@hotmail.com.

** Doutora em Educação pela Universidade Federal da Bahia. Docente do Programa de Pós-Graduação em Ciência da Informação UFBA. E-mail: anap.villalobos@terra.com.br
} 


\section{INTRODUÇÃO}

A palavra tecnologia tem origem grega, formada por Tekhne que significa, "arte, técnica, ofício", junto com o sufixo Logia que quer dizer "conhecimento, estudo de algo".

A descoberta do fogo, da roda, a escrita, são tecnologias primitivas. $O$ surgimento do computador e internet foi possível graças à evolução das tecnologias da informação e comunicação pela evolução das telecomunicações. Com isso, Castells (2005), que defende o mesmo pensar de Harvey Brook e Daniel Bell (2005, p.67) conceituam tecnologia como "o uso dos conhecimentos científicos para especificar as vias de se fazerem as coisas de maneira reproduzível". Essa reprodução no mundo cada vez mais tecnológico, ganha muito mais espaço e velocidade com as tecnologias digitais.

As tecnologias digitais estão inseridas na vida das pessoas em qualquer ambiente, seja familiar, de trabalho, nas escolas, na convivência social com amigos. E essa ligação se dá por meio dos diversos dispositivos digitais, seja o celular, tablet ou notebook.

Conforme Castells (1999),

O processo atual de transformação tecnológica expande exponencialmente em razão de sua capacidade de criar uma interface entre campos tecnológicos mediante de uma linguagem digital comum na qual a informação é gerada, armazenada, recuperada, processada e transmitida. (CASTELLS, 1999, p.50)

A tecnologia da informação segundo Le Coadic (2004) tem por objetivo "a concepção de produtos, sistemas e serviços que permitem a construção, comunicação, armazenamento e uso da informação". E esse desenvolvimento cada vez mais crescente e irrevogável das tecnologias da informação se dá por esses estudos e pesquisas constantes na área da Ciência da Informação para atender à sociedade de modo geral, em diversas áreas, dessa forma diminuir ou evitar problemas para melhoria da vida das pessoas por meio das pesquisas em informação. 
A internet propicia grande parte da velocidade com que as informações sejam disseminadas de forma rápida por meio dos dispositivos digitais. A necessidade de informação é inerente ao ser humano. O uso da informação pode propiciar conhecimento, desenvolvimento de ideias e produtos que transformam uma sociedade no intuito de atender à essas necessidades.

O que leva uma pessoa a procurar informação conforme Le Coadic é a "existência de um problema a resolver, de um objetivo a atingir e a constatação de um estado anômalo de conhecimento, insuficiente ou inadequado" (LE COADIC, 2004, p.39).

Encontrar um conceito específico para informação, principalmente com o advento da tecnologia que vêm ao longo de décadas, agregando valor a velocidade com que a informação é disseminada, não é uma tarefa fácil e que possa ser entendido como determinado conceito ser absoluto por um filósofo ou pesquisador. Weizsacker (1985) afirma não existir nenhum conceito absoluto de informação.

Outro ponto de grande relevância é como entender a informação e tecnologia na Ciência da Informação. Um dos conceitos frequentes para Ciência da Informação, segundo Capurro e Hjorland (2007, p.148) é que " $\mathrm{Cl}$ se ocupa com a geração, coleta, organização, interpretação, armazenamento, recuperação, disseminação, transformação e uso da informação, com ênfase particular, a aplicação de tecnologias modernas nestas áreas". Desse modo, não há como dissociar os estudos em informação da tecnologia em Ciência da Informação, haja vista, que juntas aprimoram os avanços tanto em pesquisas quanto em tecnologias.

2 FUNDAMENTAÇÃO TEÓRICA

De acordo com Pinheiro e Loureiro (1995), foi nos anos 30, período pósguerra mundial, que emerge o desenvolvimento científico e tecnológico, quando o capitalismo ainda impera, se deu a explosão da informação, apresentando-se como base para o crescimento econômico, tendo como lastro a ciência e tecnologia. 
Nas palavras de Loureiro (1995, p.42-53), "pelo conjunto de definições e conceitos estudados, a partir dos anos 80 , a tecnologia é definitivamente incorporada e associada à ciência da informação, o que é coerente com suas origens". Os estudos em Ciência da Informação demonstram o entrelaçamento das tecnologias da informação cada vez mais presentes na vida em sociedade e no desenvolvimento científico e tecnológico no mundo nessa área.

Como afirma Le Coadic,

A ciência da Informação tornou-se, portanto, uma ciência social rigorosa que se apoia em uma tecnologia, também rigorosa. Tem por objetivo o estudo das propriedades gerais da informação (natureza, gênese, efeitos), e a análise de seus processos de construção, comunicação e uso. (LE COADIC, 2004, p.25)

A evolução tecnológica vem atuando junto a Ciência da Informação como em diversos campos do conhecimento. Algumas pesquisas datam do final do século $\mathrm{XX}$, aproximadamente entre os anos 70 a 90 como período do surgimento das tecnologias da informação. Conforme Castells,

Instalou-se um novo paradigma tecnológico capaz de integrar, por meio de uma linguagem digital comum, a informação produzida e transmitida por diferentes tecnologias, tais como computação, telecomunicações e radiodifusão (CASTELLS, 1999, p.51-53).

Percebe-se, através da revolução tecnológica ao longo de décadas, como a sociedade modificou os hábitos das pessoas, a economia, o mercado, a forma de fazer política, no campo da ciência, enfim. Antes, tínhamos apenas a possibilidade de estudar num livro físico (no papel), na atualidade esse mesmo livro está disponível em diferentes plataformas digitais para acesso e uso.

Mediante as mudanças por meio das tecnologias, é extremamente importante analisar quais são as políticas públicas de informação, o qual é objetivo desse trabalho, pois essa busca parear a qualidade de informação que é produzida substancialmente no cotidiano e que ganhou uma velocidade ainda 
maior com a internet. Porém, o acesso, uso e disseminação da informação não se dar uniformemente entre o espaço e tempo.

Conforme Marciano,

Como em qualquer outra atividade, existem loci de produção e consumo acentuados de determinados conteúdos, gerando uma elite e uma periferia informacionais, cuja distância tende a se agravar, caso não seja tomada medidas capazes de aproximar os usuários da periferia dos meios e recursos de que necessitam para a produção e o intercâmbio de informações. Neste contexto, as políticas públicas da informação, mormente em países em desenvolvimento, assumem papel preponderante quanto à inclusão dos cidadãos como usuários e provedores habilitados das novas mídias - a informação assume um caráter de recurso nacional de altíssimo valor. (MARCIANO, 2006, p.37-50).

De acordo com Gómez (2002), a política de informação surge como tema autônomo, em nível nacional e internacional no cenário do pós-guerra. A inclusão da informação com a política se dá na esfera da intervenção estatal como estratégia de desenvolvimento científico-tecnológico.

A política de informação está ligada a governança, ou seja, a capacidade de implementação do estado nas políticas de informação. É importante ressaltar que não há uma política de informação que consiga abarcar tudo para atender todas as demandas, como não há um modelo consagrado que sirva de referência até mesmo em políticas públicas. O que existe, segundo conceito do pesquisador José Maria Jardim (2013), são princípios; balizamentos.

Os debates em torno das tecnologias móveis em sala de aula suscitam em todo o país, discussão quanto ao uso pelos estudantes. O celular, por ser uma tecnologia móvel de maior acesso à internet na atualidade, é considero por muitos profissionais da educação, como o vilão na escola. As tecnologias, principalmente as digitais móveis é uma oportunidade ou ameaça nas escolas brasileiras?

Para Moura,

O acesso a conteúdo multimédia deixou de estar limitado a um computador pessoal $(P C)$ e estendeu - se também às tecnologias móveis (Telemóvel, PDA (Computador de dimensões reduzidas), Pocket PC, Tablet PC, Notebook), proporcionando um novo paradigma educacional, o mobile learning ou aprendizagem móvel, através de dispositivos móveis. (MOURA, 2009, p.50) 
O fato é que as tecnologias digitais móveis: celular, tablet e notebook, mesmo não sendo adotadas por muitas escolas, fazem parte da vida dos estudantes fora dela. Será que o caminho é oportunizar por meio das atividades nas escolas, novas possibilidades de ensinar e aprender tendo as tecnologias móveis como aliada? Ou proibir o uso porque a escola vê como uma ameaça o uso dessas tecnologias em sala de aula, por ainda não ter uma política de informação digital estruturada para lidar com esses estudantes antenados na atualidade com as tecnologias móveis?

A Unesco afirma que,

Nos próximos 15 anos a tecnologia passará por grandes transformações que poderão ser alavancadas para a educação. É importante que os educadores entendam essas inovações para que possam influenciar o seu desenvolvimento, ao invés de simplesmente reagir a elas. (UNESCO, 2014, p. 25)

Obviamente, que mediante as discussões que pairam sobre o uso das tecnologias nas escolas, em maior, menor ou nenhum uso, muitas são as experiências exitosas dos estudantes nas escolas com as tecnologias digitais móveis. Há unidades escolares de referência no mundo que possuem estruturas tecnológicas e incentivam, dentro das escolas, atividades que promovam a ciência, tecnologia e inovação. No Brasil, temos escolas consideradas como referência no uso das tecnologias digitais, as quais relatamos nessa pesquisa.

\section{METODOLOGIA}

Nessa pesquisa objetivou-se analisar as políticas de informação digital adotadas nas escolas públicas de ensino médio das capitais, localizadas na região Nordeste, no tocante a adoção dos dispositivos móveis para acesso a informação. Com objetivos específicos, foram mapeadas as escolas para fazer parte da amostra pesquisada. Em seguida a identificação dos dispositivos móveis utilizados nas escolas estudadas e a investigação das consequências da utilização ou da não utilização dos dispositivos móveis para acesso à 
informação e por fim entender as razões da adoção ou não dos dispositivos móveis pelas escolas para fazer parte da investigação.

Trata-se de uma pesquisa descritiva, com uma abordagem que se caracteriza enquanto qualitativa e quantitativa. Os procedimentos adotados se referem ao estudo de casos múltiplos e as técnicas basearam-se em questionários com professores das nove unidades federativas da região Nordeste.

Entende-se a importância de estudar as políticas de informação digital adotadas na região Nordeste no tocante a adoção dos dispositivos móveis para acesso a informação, após uma pesquisa ampla com outras regiões brasileiras. A partir desse recorte, consultamos por meio de um questionário específico, contato via e-mail com os núcleos de tecnologias das secretarias de educação das nove unidades federativas da região Nordeste, como também o núcleo de tecnologias do Ministério da Educação (MEC), Ministério da Ciência, Tecnologia, Inovação e Comunicação (MCTIC) e Secretarias de Ciência, Tecnologia e Inovação de cada estado nordestino para saber sobre as políticas de informação adotadas quanto ao uso das tecnologias digitais nas escolas.

Depois da coleta das informações, passamos para a etapa de identificação de uma escola de ensino médio de capital nordestina. Os professores das escolas pesquisadas foram consultados por meio de um questionário enviado por correio eletrônico. Vale ressaltar que foi elaborado um único questionário para todos os professores das escolas. $\mathrm{O}$ questionário da pesquisa procurou investigar o conceito que o professor (a) tem sobre o uso das tecnologias digitais móveis em sala de aula, quais dispositivos são adotados, os resultados alcançados se existem dificuldades no uso dessas tecnologias em sala, qual a frequência do uso nas aulas, qual a tecnologia digital mais adotada entre o celular, tablet e notebook e como é a experiência com o uso da tecnologia digital em sala de aula. Esses dados foram coletados entre os meses de novembro de 2016 a abril de 2017. 


\section{RESULTADOS DA PESQUISA: DESCRIÇÃO E ANÁLISE}

Após uma pesquisa por questionário, via correio eletrônico com as Secretarias de Educação por meio dos seus Núcleos de Tecnologias na região Nordeste para saber como se dá o uso do celular, tablet e notebook nas escolas de ensino médio das capitais, obtiveram os seguintes resultados, os quais descrevemos abaixo.

Nota-se que Pernambuco é o único estado da região Nordeste que restringe o uso do celular em sala de aula por meio da Lei $n^{\circ} 15.507$, de 21 de maio de 2015. Os demais estados da região afirmam não possuir uma legislação que regulamente ou não o uso. Contudo, cada unidade escolar tem autonomia para determinar o uso por meio do Projeto Político Pedagógico.

A utilização do tablet não foi constatada apenas no estado do Piauí e em relação ao notebook, observa-se a adoção nas escolas da Bahia, Ceará, Pernambuco (para professores), Rio Grande do Norte e Sergipe.

De posse das informações acima dos Núcleos de Tecnologias das Secretarias de Educação no Nordeste, pesquisamos uma (01) escola do ensino médio de cada capital, onde foram consultados os professores da escola por meio de um questionário enviado via correio eletrônico sobre o uso das tecnologias digitais móveis, seja o celular, tablet e notebook se são adotadas em sala de aula. Após receber as informações dos professores que cada escola pesquisada, desenvolvemos uma análise comparativa. Essa análise busca comparar as informações dos núcleos de Tecnologias das Secretarias de Educação com a realidade da escola pesquisada. A seguir a análise comparativa entre as Secretarias de Educação da região Nordeste com as escolas pesquisadas.

Tabela 1 - Análise Comparativa entre a Secretaria de Educação e Escola em Maceió $(\mathrm{AL})$

\begin{tabular}{|l|l|}
\hline $\begin{array}{l}\text { Secretaria de Educação } \\
\text { de Alagoas (Maceió) }\end{array}$ & $\begin{array}{l}\text { Distribuição entre os professores de tablets. Sem } \\
\text { registro de uso do celular e notebook nas escolas. }\end{array}$ \\
\hline $\begin{array}{l}\text { Escola Geraldo Melo em } \\
\text { Maceió. }\end{array}$ & $\begin{array}{l}\text { Celular e Notebook: Tecnologias adotadas por um } \\
\text { professor. }\end{array}$ \\
\hline
\end{tabular}

Fonte: Autoras

Inf. Inf., Londrina, v. 22, n. 2, p. 356 - 370, maio/ago., 2017. http:www.uel.br/revistas/informacao/ 
Tabela 2 - Análise Comparativa entre a Secretaria de Educação e Escola em Salvador (BA)

\begin{tabular}{|l|l|}
\hline $\begin{array}{l}\text { Secretaria de Educação } \\
\text { da Bahia (Salvador) }\end{array}$ & $\begin{array}{l}\text { Registro de uso do celular na escola. Não foi } \\
\text { registrado uso do tablet e notebook em sala de } \\
\text { aula. }\end{array}$ \\
\hline $\begin{array}{l}\text { Colégio Estadual Odorico } \\
\text { Tavares em Salvador }\end{array}$ & $\begin{array}{l}\text { Celular e Notebook são tecnologias adotadas por } \\
\text { professores. }\end{array}$ \\
\hline
\end{tabular}

Fonte: Autoras

Tabela 3 - Análise Comparativa entre a Secretaria de Educação e Escola em Fortaleza (CE)

\begin{tabular}{|l|l|}
\hline $\begin{array}{l}\text { Secretaria de Educação } \\
\text { do Ceará (Fortaleza) }\end{array}$ & $\begin{array}{l}\text { Sem registro de uso do celular em sala de aula. } \\
\text { Dispõe de tablets educacionais. Registro de 06 } \\
\text { escolas contempladas com Laptops no Projeto "Um } \\
\text { Computador por Aluno". }\end{array}$ \\
\hline $\begin{array}{l}\text { Escola Estadual de } \\
\begin{array}{l}\text { Educação Profissional } \\
\text { Jaime Alencar de Oliveira } \\
\text { em Fortaleza. }\end{array}\end{array}$ & $\begin{array}{l}\text { Celular, tablet e Notebook: São tecnologias digitais } \\
\text { adotadas pelos professores em sala de aula. }\end{array}$ \\
\hline
\end{tabular}

Fonte: Autoras

Tabela 4 - Análise Comparativa entre a Secretaria de Educação e Escola em São Luís (MA)

\begin{tabular}{|l|l|}
\hline $\begin{array}{l}\text { Secretaria de Educação } \\
\text { do Maranhão (São Luís) }\end{array}$ & $\begin{array}{l}\text { Sem registro de experiências com o celular em } \\
\text { sala de aula. Dispõe de tablets educacionais do } \\
\text { Proinfo nas escolas. Não foi mencionado o uso do } \\
\text { notebook. }\end{array}$ \\
\hline $\begin{array}{l}\text { Centro de Ensino } \\
\text { Professora Margarida } \\
\text { Pires Leal em São Luís. }\end{array}$ & $\begin{array}{l}\text { Nenhum professor da escola respondeu a } \\
\text { pesquisa. }\end{array}$ \\
\hline
\end{tabular}

Fonte: Autoras

Inf. Inf., Londrina, v. 22, n. 2, p. 356 - 370, maio/ago., 2017. http:www.uel.br/revistas/informacao/ 
Tabela 5 - Análise Comparativa entre a Secretaria de Educação e Escola em João Pessoa (PB)

\begin{tabular}{|l|l|}
\hline $\begin{array}{l}\text { Secretaria de Educação } \\
\text { da Paraíba (João Pessoa) }\end{array}$ & $\begin{array}{l}\text { Sem registro de uso do celular em sala de aula. } \\
\text { Incentivam o uso do tablet com cessão para os } \\
\text { estudantes do ensino médio. Sem registro de } \\
\text { atividades com o notebook nas escolas. }\end{array}$ \\
\hline $\begin{array}{l}\text { Escola Cidadã Integral } \\
\text { Técnica Pastor João } \\
\begin{array}{l}\text { Pereira Gomes Filho em } \\
\text { João Pessoa. }\end{array}\end{array}$ & $\begin{array}{l}\text { Celular e Notebook: São as tecnologias adotadas } \\
\text { pelos professores nas aulas. Com o tablet não há } \\
\text { registro. }\end{array}$ \\
\hline
\end{tabular}

Fonte: Autora

Tabela 6 - Análise Comparativa entre a Secretaria de Educação e Escola em Recife (PE)

\begin{tabular}{|l|l|}
\hline $\begin{array}{l}\text { Secretaria de Educação } \\
\text { do Estado de }\end{array}$ & $\begin{array}{l}\text { A Lei n 15.507, de 21 de maio de } 2015 \\
\text { regulamenta o uso do celular nas escolas. Uso do } \\
\text { tablet na aplicação da metodologia Mind Lab no } \\
\text { Programa Mente Inovadora e distribuição para os } \\
\text { professores do notebook no Programa " Professor } \\
\text { Conectado". }\end{array}$ \\
\hline $\begin{array}{l}\text { Escola Aníbal Fernandes } \\
\text { em Recife. }\end{array}$ & $\begin{array}{l}\text { O celular e o notebook sendo o mais utilizado o } \\
\text { notebook. }\end{array}$ \\
\hline
\end{tabular}

Fonte: Autoras

Tabela 7- Análise Comparativa entre a Secretaria de Educação e Escola em Teresina $(\mathrm{PI})$

Secretaria de Educação Não há uma diretriz única para as escolas, uma vez do Estado de Piauí que cada unidade pode definir as regras para uso

(Teresina) ou não das tecnologias digitais. Sem registro do uso de celular, tablet e notebook em sala de aula.

Centro de Ensino Integral $\mid$ notebook é a tecnologia digital móvel adotada João Henrique de pelos professores.

Almeida em Teresina.

Fonte: Autoras

Inf. Inf., Londrina, v. 22, n. 2, p. 356 - 370, maio/ago., 2017. http:www.uel.br/revistas/informacao/ 
Tabela 8 - Análise Comparativa entre a Secretaria de Educação e Escola em Natal (RN)

\begin{tabular}{|l|l|}
\hline $\begin{array}{l}\text { Secretaria de Educação } \\
\text { do Rio Grande do Norte } \\
\text { (Natal) }\end{array}$ & $\begin{array}{l}\text { Sem registro de uso do celular em sala de aula. As } \\
\text { escolas receberam tablets e notebook para uso com } \\
\text { o SigEduc e Portais Educacionais. }\end{array}$ \\
\hline $\begin{array}{l}\text { Colégio Estadual do } \\
\text { Atheneu Norte Rio - } \\
\text { Grandense em Natal. }\end{array}$ & $\begin{array}{l}\text { Celular, tablet e notebook são as tecnologias } \\
\text { digitais móveis adotados pelos professores. Sendo } \\
\text { o notebook e o celular mais adotados. }\end{array}$ \\
\hline
\end{tabular}

Fonte: Autoras

Tabela 9 - Análise Comparativa entre a Secretaria de Educação e Escola em Aracaju (SE)

\begin{tabular}{|l|l|}
\hline $\begin{array}{l}\text { Secretaria de Educação } \\
\text { do Estado de Sergipe }\end{array}$ & $\begin{array}{l}\text { Sem registro de uso do celular em sala de aula. Há } \\
\text { registro de 07 (sete) escolas com o uso de tablets } \\
\text { cedidos pelo Prolnfo e sem registro de notebook } \\
\text { para escolas de ensino médio. }\end{array}$ \\
\hline $\begin{array}{l}\text { Colégio Estadual Cícero } \\
\text { Bezerra em Aracaju. }\end{array}$ & $\begin{array}{l}\text { Celular, tablet e notebook são tecnologias digitais } \\
\text { na escola, sendo o mais utilizado o notebook. }\end{array}$ \\
\hline
\end{tabular}

Fonte: Autoras

De posse das informações dos Núcleos de Tecnologias das Secretariais de Educação da região Nordeste sobre o uso das tecnologias digitais móveis em sala de aula, nota-se a partir da pesquisa realizada com os professores das unidades escolares de ensino médio da capital de cada estado nordestino que foram escolhidas para compor o objeto de estudo dessa pesquisa, percebe-se que em alguns estados da região Nordeste, as Secretarias de Educação não possuem informações atualizadas das tecnologias digitais: celular, tablet e notebook que são adotadas pelos docentes em sala de aula.

Dessa forma a pesquisa demonstra, com base na entrevista realizada com professores das escolas de ensino médio da capital da região Nordeste, quais são os dispositivos digitais móveis mais utilizados pelos docentes em sala de aula por proporcionarem melhor resultado quanto à exposição dos conteúdos estudados e melhor apreensão por parte dos alunos quanto à aquisição de conhecimento.

A pesquisa demonstra também que o tablet, um dispositivo móvel 
oferecido pelo Ministério da Educação em muitas escolas públicas da região Nordeste, principalmente para uso dos professores, é uma das tecnologias móveis menos utilizadas pelos professores em sala de aula. $\mathrm{O}$ celular e $\mathrm{o}$ notebook são as ferramentas mais utilizadas pelos professores, conforme identificados na pesquisa.

\section{CONCLUSÃO}

Essa pesquisa abordou as tecnologias digitais em três diferentes dispositivos: o celular, tablet e notebook, analisando como se dá o uso dessas tecnologias digitais nas escolas públicas em diferentes estados brasileiros da região Nordeste. Foram analisadas 9 escolas de ensino médio, sendo 01(uma) em cada capital dos estados nordestinos e 26 professores que contribuíram de forma espontânea para demonstrar o panorama das políticas de informação digital adotadas nas escolas públicas da região Nordeste.

Nessa pesquisa identificamos um dos paradigmas epistemológicos propostos por Capurro (2003) na área da Ciência da Informação: o paradigma social. Capurro (2003, p.9) "considera paradigma como um modelo abstrato que possibilita ver uma coisa em analogia à outra". Dentre os paradigmas defendidos por ele está o paradigma social, observado nesse estudo.

Conforme Capurro,

Uma consequência prática deste paradigma é "o de abandonar a busca de uma linguagem ideal para representar 0 conhecimento ou de um algoritmo ideal para modelar a recuperação da informação, como aspiram o paradigma físico e o cognitivo. (CAPURRO, 2003, p.9)

Desse modo, busca-se valorizar o contexto social do usuário da informação nesse paradigma, o que ocorre nessa pesquisa onde cada estado da região Nordeste adota políticas diferenciadas de acordo o universo que está inserido e com peculiaridades distintas culturalmente. É perceptível, nas escolas públicas pesquisadas de ensino médio da capital na região Nordeste, a adoção de algumas tecnologias digitais móveis em detrimento de outras, o posicionamento dos professores com relação às mesmas e as condições do ambiente onde estão inseridos. 
Para realizar essa pesquisa foram mapeadas as escolas para fazerem parte da pesquisa, aplicação de um questionário aos professores do ensino médio para identificar os dispositivos digitais móveis que são usados em sala de aula e identificação da qualidade da informação por meio dessa tecnologia digital que é acessada e usada dentro da escola.

Em Fortaleza (CE) identificamos uma sintonia entre o Núcleo de Tecnologia Educacional da Secretaria de Educação do estado do Ceará, a escola, tecnologias digitais e professores, o que demonstra a existência de uma ação conjunta para executar a política de informação digital na escola pesquisada. Um outro fator relevante é que essa escola Estadual de Ensino Profissionalizante Jaime Alencar de Oliveira faz parte das 33 escolas piloto no estado do Ceará na implantação do sistema do diário de classe online, o qual é utilizado para divulgação e acompanhamento das informações acadêmicas dos alunos.

Na sequência está a escola estadual em João Pessoa que demonstra ações positivas quanto as políticas de informação digital dentro da escola. $O$ colégio Pastor João Pereira Gomes entende o uso das tecnologias digitais na escola como aliadas as atividades que são desenvolvidas pelos professores em sala de aula. Identificamos uma parceria entre o Núcleo de Tecnologia Educacional da Secretaria de Educação do estado da Paraíba em consonância com o que é desenvolvido na escola.

A formulação de uma política, nesse estudo, de informação digital para a educação não depende unicamente da escola, pelo simples fato de possuir autonomia para desenvolver suas ações. É necessária uma ação conjunta na criação de uma agenda para formulação de ações para atender à necessidade da chamada "inclusão digital na educação" que deve contar com a Secretaria de Educação, Núcleos de Tecnologias voltados para a educação, diretores de escolas, professores e alunos.

Entretanto, é relevante por parte de algumas Secretarias de Educação da região Nordeste mais incentivo e apoio às escolas no tocante a fomentar uma política de informação digital no ensino médio. Essa pesquisa identificou exemplos de políticas de informação digital nas escolas em Fortaleza (CE) e 
João Pessoa (PB) que podem servir como base na criação de uma política de informação digital em outros estados.

\section{REFERÊNCIAS}

CAPURRO, R. Epistemologia e Ciência da informação. In: V Encontro Nacional de Pesquisa em Ciência da Informação, 5, Belo Horizonte, 2003. Anais... Belo Horizonte: Escola de Ciência da Informação da UFMG, 2003. 1 cd-rom.

CAPURRO, R.; HJORLAND, B. O conceito de informação. Perspectivas em Ciência da Informação, Belo Horizonte, v.12, n.1, p.148-207, abr. 2007.

CASTELLS, M. A. sociedade em rede. São Paulo: Paz e Terra, 1999.

A Sociedade em Rede: a era da informação, economia, sociedade e cultura. 8. ed. Traduzido por Klauss Brandini Gerhardt e Roneide Vanancio Majer. São Paulo: Paz e Terra, 2005.

JARDIM, J. M. Seminário Gestão da Memória. Youtube, 17 jul. 2013. Disponível em: $<$ https://www.youtube.com/watch?v=kk-UtycbYJl>. Acesso em: 12 ago. 2016.

PINHEIRO, L.V.R.; LOUREIRO, J.M.M. Traçados e limites da ciência da informação.

Ciência da Informação, v.24, n.1, p.42-53, 1995.

LE COADIC, Y. F. A ciência da informação. Tradução de Maria Yêda F. S de Filgueiras Gomes. 2. ed. Brasília, DF: Briquet de Lemos, 2004.

MARCIANO, J. L. P. Bases teóricas para a formulação de políticas de informação, Informação \& Sociedade: Estudos, v. 16, n. 2, p.37-50, 2006.

MOURA, A. Geração Móvel: um ambiente de aprendizagem suportado por tecnologias móveis para a Geração Polegar. Disponível em:

$<$ https://repositorium.sdum.uminho.pt/bitstream/1822/10056/1/Moura $\% 2520 \% 282009 \%$ 29\%2520Challenges.pdf>. Acesso em 14 de mar. 2017.

UNESCO. Diretrizes de políticas da UNESCO para a aprendizagem móvel. UNESCO. Paris, p. 41. 2014.

WEISACKER, C. F. Von. Aufbau der Physik (Foundation of physics). Munich: Hanser, 1985.

\section{Title}

The digital information policies adopted in public schools in the northeast

\section{Abstract:}

Introduction: Experiences in education with digital technology in the classroom are verified in different Brazilian regions, made possible through the various digital devices, 
be it the cell phone, tablet or notebook. Objectives: To analyze the digital information policies adopted in the public high schools of the capitals, located in the Northeast region, regarding the adoption of mobile devices for access to information. Methodology: This is descriptive research, with an approach that is characterized as qualitative and quantitative. The procedures adopted refer to the study of multiple cases and the techniques were based on questionnaires with teachers from the nine federative units of the Northeast region. Results: The tablet is one of the least used mobile technologies by teachers. The mobile and the notebook are work tools most used by teachers in class, finding no difficulty in using and the results obtained with these mobile technologies in the classroom, add value in the acquisition of knowledge regarding the classes without the aid of these technologies. Conclusion: Examples of digital information policies were identified in schools in Fortaleza (CE) and João Pessoa (PB), which can serve as a basis for the creation of a digital information policy in other states.

Keywords: Information Technology. Mobile device. Digital Information Policy. Use of cell phone, tablet and notebook. Education in the Brazilian Northeast.

\section{Titulo}

Las políticas de información digital adoptadas en las escuelas públicas en el nordeste

\section{Resumen:}

Introducción: Las experiencias en la educación con la tecnología digital en el aula se verifican en diferentes regiones brasileñas, viabilizadas a través de los diversos dispositivos digitales, sea el celular, tablet o notebook. Objetivos: Analizar las políticas de información digital adoptadas en las escuelas públicas de enseñanza media de las capitales, ubicadas en la región Nordeste, en lo que se refiere a la adopción de los dispositivos móviles para acceso a la información. Metodología: Se trata de una investigación descriptiva, con un enfoque que se caracteriza como cualitativa y cuantitativa. Los procedimientos adoptados se refieren al estudio de casos múltiples y las técnicas se basaron en cuestionarios con profesores de las nueve unidades federativas de la región Nordeste. Resultados: La tableta es una de las tecnologías móviles menos utilizadas por los profesores. El celular y el portátil son herramientas de trabajo más utilizadas por los profesores en las aulas, no encontrando ninguna dificultad en el uso y los resultados obtenidos con esas tecnologías móviles en el aula, agregan valor en la adquisición del conocimiento con respecto a las clases sin el auxilio de esas tecnologías. Conclusión: Se identificaron ejemplos de políticas de información digital en las escuelas en Fortaleza (CE) y en João Pessoa (PB) que pueden servir como base en la creación de una política de información digital en otros estados.

Palabras clave: Tecnología de la información. Dispositivo móvil. Política de información digital. Uso del celular, tablet y notebook. Educação no Nordeste brasileiro.

Recebido: 30.08 .2017

Aceito: 30.09 .2017

Inf. Inf., Londrina, v. 22, n. 2, p. 356 - 370, maio/ago., 2017.

http:www.uel.br/revistas/informacao/ 